\title{
Treatment of severe pain in a patient with complex regional pain syndrome undergoing dental treatment under general anesthesia: A case report
}

\author{
Seung-Hyun Rhee ${ }^{1 *}$, Sang-Hun Park ${ }^{2 *}$, Sung-Ho Ha², Seung-Hwa Ryoo ${ }^{1}$, Myong-Hwan Karm', \\ Hyun Jeong $\mathrm{Kim}^{3}$, Kwang-Suk $\mathrm{Seo}^{3}$ \\ 1Department of Dental Anesthesiology, Seoul National University Dental Hospital, Seoul, Korea \\ ${ }^{2}$ Department of Oral and Maxillofacial Surgery, Seoul National University Dental Hospital, Seoul, Korea \\ ${ }^{3}$ Department of Dental Anesthesiology and Dental Research Institute, School of Dentistry, Seoul National University, Seoul, Korea
}

\begin{abstract}
Complex regional pain syndrome (CRPS) is rare, characterized by pain from diverse causes, and presents as extreme pain even with minor irritation. General anesthesia may be required for dental treatment because the pain may not be controlled with local anesthesia. However, treatment under general anesthesia is also challenging. A 38-year-old woman with CRPS arrived for outpatient dental treatment under general anesthesia. At the fourth general anesthesia induction, she experienced severe pain resulting from her right toe touching the dental chair. Anesthesia was induced to calm her and continue the treatment. After 55 minutes of general anesthesia, the patient still complained of extreme toe pain. Subsequently, two administrations for intravenous sedation were performed, and discharge was possible in the recovery room approximately $5 \mathrm{~h}$ after the pain onset. The pain was not located at the dental treatment site. Although the major factor causing pain relief was unknown, ketamine may have played a role.
\end{abstract}

Keywords: Complex Regional Pain Syndromes; Dental Care; Pain Management.

This is an Open Access article distributed under the terms of the Creative Commons Attribution Non-Commercial License (http://creativecommons.org/licenses/by-nc/4.0/) which permits unrestricted non-commercial use, distribution, and reproduction in any medium, provided the original work is properly cited.

\section{INTRODUCTION}

Complex regional pain syndrome (CRPS) is characterized by pain and sensory, autonomic, trophic, and motor abnormalities [1]. Patients with CRPS often complain of extreme pain even with minor irritation or tooth extraction under local anesthesia. If dental treatment under local anesthesia is not possible, general anesthesia may be considered. CRPS is rarely encountered in the dental office, and only a few studies report dental treatment of patients with CRPS. Patients with CRPS experience pain and anxiety, making dental treatment challenging, even under general anesthesia.

Herein, we report a case of severe pain during dental treatment caused by mechanical stimulation in a patient with CRPS, which did not disappear after the treatment under general anesthesia but was relieved through intravenous sedation with ketamine.

Received: October 17, 2019 • Revised: October 22, 2019 • Accepted: October 25, 2019

Corresponding Author: Kwang-Suk Seo, Department of Dental Anesthesiology, School of Dentistry, Seoul National University, 101, Daehak-ro, Jongno-gu, Seoul, Korea

Tel: +82-2072-0622 Fax: +82-2-766-9427 Email: stone90@snu.ac.kr

${ }^{*} \mathrm{RSH}$ and PSH contributed equally to this work.

Copyright@ 2019 Journal of Dental Anesthesia and Pain Medicine 


\section{CASE REPORT}

A 38-year-old woman, with the chief complaint of multiple caries, was referred to the Department of Dental Anesthesiology from the Department of Conservative Dentistry, Seoul National University Dental Hospital, for treatment under general anesthesia, because she could not endure pain under local anesthesia. She was diagnosed with osteoporosis and type I CRPS and was undergoing treatment. The symptoms of CRPS began 18 years ago following percutaneous endoscopic laser discectomy. The symptoms began in the lower back and hips spreading all over the body. She feels extreme pain even during urination and defecation. She received a morphine pump implantation 2 years ago and is receiving continuous infusion of morphine $4.33 \mathrm{mg}$ per day, to a maximum of 5 times of $0.499 \mathrm{mg}$ bolus a day when needed. Tweleve to fifteen tablets of $5 \mathrm{mg}$ oxycodone were taken 10 times a day and $600 \mathrm{mg}$ gabapentin were taken 3 times a day. She was also treated with ketamine $100 \mathrm{mg}$, midazolam $5 \mathrm{mg}$ and dexmedetomidine $200 \mu \mathrm{g}$ intravenous sedation weekly for pain control. Patient described her pain as 5 with visual analog scale (VAS) even without stimulation. She weighed $72 \mathrm{~kg}$ and had an American Society of Anesthesiologists 2 physical status with no other cardiovascular or respiratory diseases.

General anesthesia was induced four times for multiple tooth caries treatment. Twelve teeth $(\# 15, \# 22, \# 23, \# 25$, \#26, \#34, \#35, \#36, \#37, \#44, \#45, and \#46) were restored with resin. Endodontic treatment was performed for three teeth (\#31, \#32, \#47), and one tooth (\#24) was extracted.

In the operating room, intravenous access was established with a 22-gauge cannula on the left arm. Electrocardiography leads or blood pressure cuffs were not applied because of possible pain. Only pulse oximetry was performed. General anesthesia was induced with propofol and remifentanil. In addition, dexmedetomidine was infused continuously to reduce pain. Therefore, pain at the dental treatment site and throat pain due to endotracheal intubation were tolerable. Patient did not

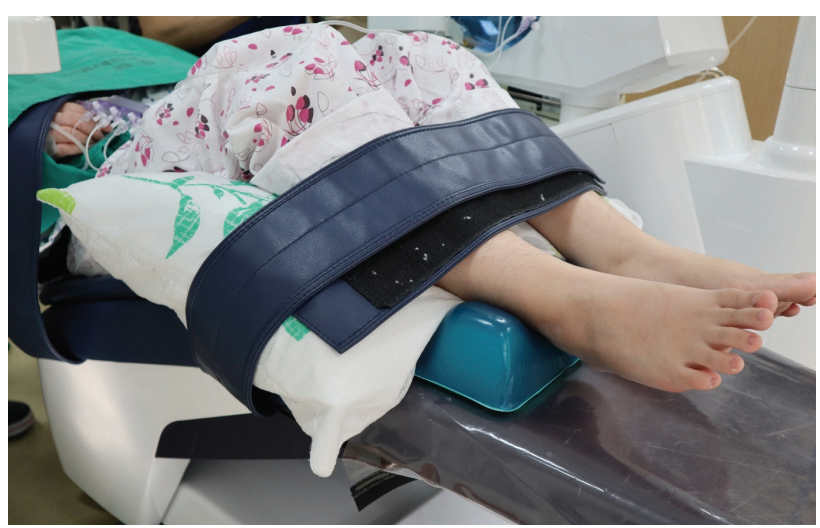

Fig. 1. Pillows are placed under the knee and secured to the bed with a restraining band during general anesthesia of a patient with complex regional pain syndrome

complain about dressing site on the face or sites of electrocardiography lead or blood pressure cuff. The intraoperative course was uneventful.

However, during the preparation for the fourth general anesthesia induction, the patient's right toe touched the dental chair and immediately developed severe pain. Considering the hitting sound and physical examination of the injured site, the injury was not serious, but the patient complained of severe pain. She described her toe pain as VAS 9 to 10 . Induction was initiated to calm the patient and continue the treatment. Initiation and maintenance of anesthesia proceeded in the same manner as the previous three times. After sufficient preoxygenation, $30 \mathrm{mg}$ bolus administration of $1 \%$ lidocaine was performed. In the dorsal veins of the hand, $4.0 \mathrm{ng} / \mathrm{mL}$ of remifentanil and $4.0 \mu \mathrm{g} / \mathrm{mL}$ of propofol were administered with continuous, target-controlled infusion (TCI). For neuromuscular blockade, a $50 \mathrm{mg}$ bolus of rocuronium was administered. After nasotracheal intubation, propofol and remifentanil were reduced to maintenance doses of $3.0 \mu \mathrm{g} / \mathrm{mL}$ and $3.0 \mathrm{ng} / \mathrm{mL}$, respectively. Dexmedetomidine was started with continuous infusion to reduce pain. To prevent further injuries, pillows were placed under the knee and secured to the bed with a restraining band (Fig. 1). After $55 \mathrm{~min}$ of dental treatment, the total intravenous anesthesia was terminated. To restore spontaneous breathing, $0.8 \mathrm{mg}$ of glycopyrrolate and $15 \mathrm{mg}$ of pyridostigmine were 


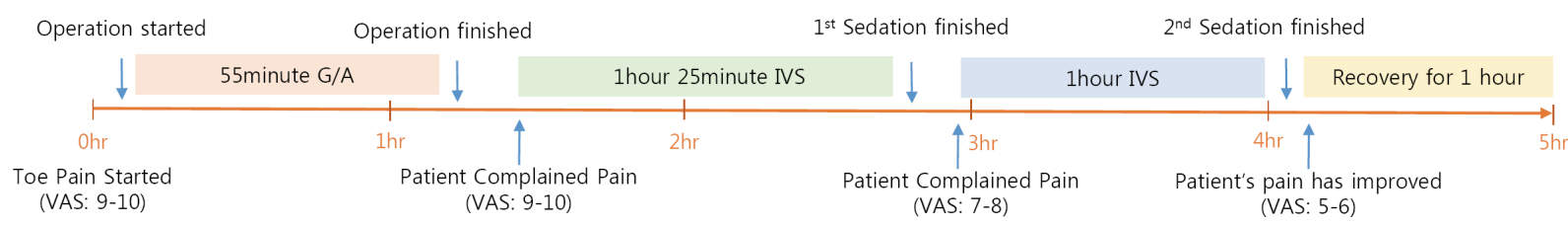

\begin{tabular}{|c|c|c|c|c|}
\hline Propofol & $\mathrm{TCI}(3.0 \sim 4.0 \mu \mathrm{g} / \mathrm{ml})$ & $\mathrm{TCI}(1.0 \sim 3.0 \mu \mathrm{g} / \mathrm{ml})$ & & \multirow{5}{*}{ Recovery } \\
\hline Remifentanil & TCI $(3.0 \sim 4.0 \mathrm{ng} / \mathrm{ml})$ & & & \\
\hline Dexmedetomidine & $\begin{array}{c}\text { Infusion }(0.5 \sim 1 \mu \mathrm{g} / \mathrm{kg} / \mathrm{h}) \\
\text { in } 45 \mathrm{~min}\end{array}$ & $\begin{array}{c}\text { Infusion }(0.5 \sim 1 \mu \mathrm{g} / \mathrm{kg} / \mathrm{h}) \\
\text { in } 45 \mathrm{~min}\end{array}$ & infusion $0.5 \mu \mathrm{g} / \mathrm{kg} / \mathrm{h}$ in $5 \mathrm{~min}$ & \\
\hline Midazolam & & & Bolus (5mg) & \\
\hline Ketamine & & & Bolus (100mg) & \\
\hline
\end{tabular}

G/A: General anesthesia, IVS: Intravenous sedation, TCI: Target-Controlled Infusion

Fig. 2. Time table and drug usage of anesthesia

injected. To prevent postoperative nausea and vomiting, $0.3 \mathrm{mg}$ of ramosetron hydrochloride was also injected.

The patient was transferred to the recovery room. She complained of extreme pain in the right toe that was injured before the operation but not in the dental treatment area. According to the medical report, the patient had been treated for CRPS with intravenous sedation, using dexmedetomidine $(0.5 \sim 1 \mu \mathrm{g} / \mathrm{kg} / \mathrm{h}$ infusion in $45 \mathrm{~min})$ and propofol $(1.0 \sim 3.0 \mu \mathrm{g} / \mathrm{ml} \mathrm{TCI}$ in $1 \mathrm{~h})$ to reduce pain and recover safely. The patient was moderately sedated. One hour after the first sedation, toe pain still persisted after the patient restored consciousness, and she had no improvement in symptoms that were present before the sedation. For repeat sedation, $5 \mathrm{mg}$ of midazolam and $100 \mathrm{mg}$ of ketamine were used. After $1 \mathrm{~h}$, her consciousness restored. After the second sedation, the pain had persisted, but she felt better than before, and the consciousness level was clear (Fig. 2). Subsequently, she was discharged normally. After $5 \mathrm{~h}$, she sustained an injury in the toe but did not complain of toe pain at the next visit.

\section{DISCUSSION}

Patients with CRPS are rarely encountered by dentists, but understanding their pain management can be helpful. Pain-induced nerve lesions are classified as unidentifiable type I CRPS and verifiable type II CRPS [2]. In 1994, the International Association for the Study of Pain (IASP) published diagnostic criteria for CRPS [3], including: 1) presence of an inciting event; 2) continuation of disproportionate pain, allodynia, and hyperalgesia; 3) skin changes, edema, and abnormal sudomotor activity; and 4) absence of other conditions that may account for the pain and dysfunction. However, these criteria have poor specificity and lead to overdiagnosis [4]. In 2010, an international consensus meeting was held in Budapest, in which diagnostic criteria for CRPS were defined (Table 1) [5].

The incidence of CRPS is unclear. A population-based study conducted from 1996 to 2005 reported it to be 26.2 per 100,000 person-year in the Netherlands. The incidence increases with age, until 70 years, and is $3-4$ times more common in women than in men. The contributing factors are fracture $(45 \%)$, sprain $(18 \%)$, and elective surgeries (about 12\%) [6]. However, all individuals sustaining these injuries do not develop symptoms of CRPS. The individual predisposing factors may include psychological factors, immobilization of the injured extremities, and genetics.

Medications such as non-steroidal anti-inflammatory 
Table 1. Budapest Criteria for the diagnosis of complex regional pain syndrome

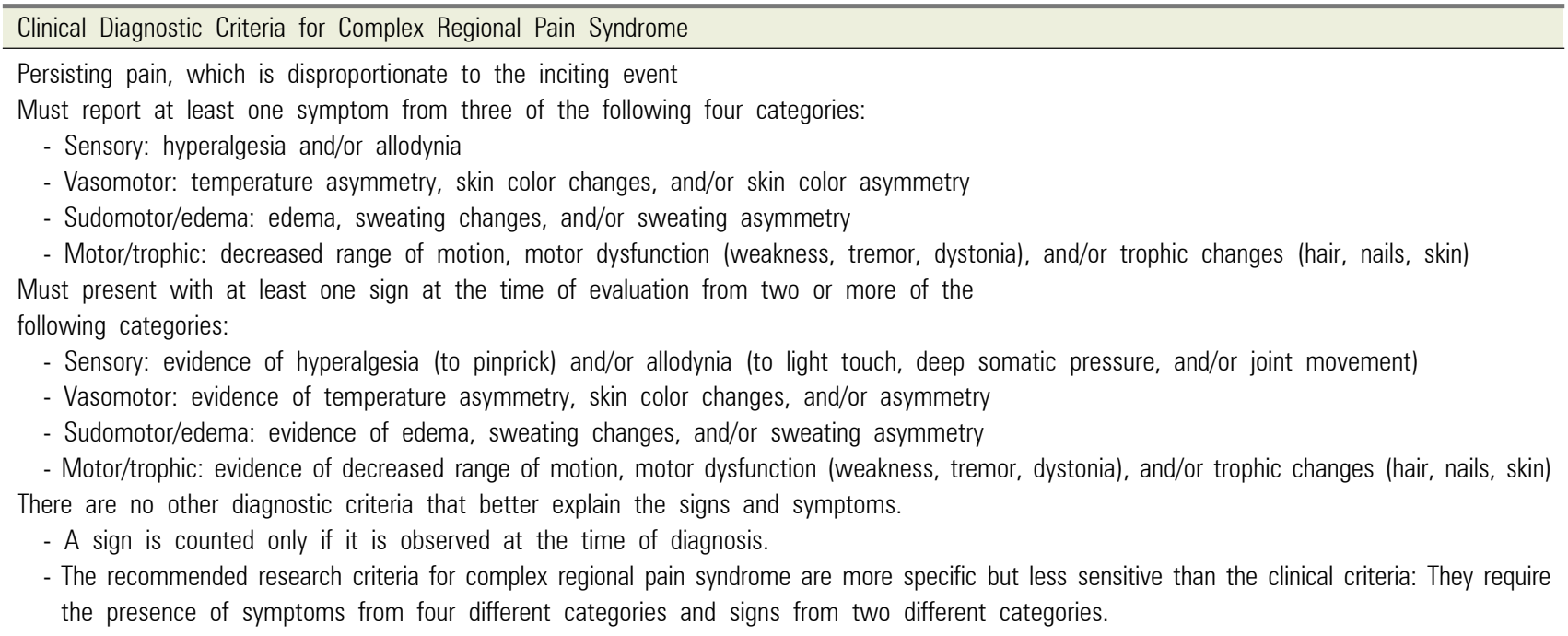

Table 2. Key patient information

CRPS is an uncommon nerve pain disorder of the arms or legs.

CRPS is generally preceded by an injury but the cause is poorly understood.

Pain persists after the original injury has healed.

There is no specific cure.

This pain can lead to anxiety, depression, lack of sleep, disability, and distress.

Pain cannot be prevented in patients with CRPS.

CRPS is not hereditary.

The condition can improve unaided or with specialized treatment and antiepileptic or antidepressant medications.

The doctor may refer the patient to a multidisciplinary team for the specialized treatment.

The aim is to improve the limb function with the help of physiotherapists and occupational therapists.

drugs, steroids (immunomodulator), ion-channel blockers (gabapentin, carbamazepine), antidepressants (serotonin and norepinephrine reuptake inhibitors), opioids, N-methyl-D aspartate receptor (NMDAR) antagonists (ketamine), and bisphosphonates are the main treatment options for patients with CRPS [7-9]. In addition, a sympathetic nerve block, stellate ganglion block, intravenous regional block, transcutaneous electrical stimulation, and physical therapy can help reduce the symptoms.

Although there are numerous theories regarding the origin and progression of CRPS, the exact cause is unknown. The recent concepts regarding their pathophysiology include inflammatory processes, sympathetically mediated conditions, central sensitization, ischemia-reperfusion injury, cortical reorganization, small-fiber neuropathy, sensitivity to neuropeptides, psychological stress, genetics, and auto-immune disorders [10]. Although infection is considered the primary pathophysiological mechanism, other factors can also be considered.

The diagnostic criteria called the Budapest criteria has high specificity and sensitivity compared to IASP (Table 1). However, there are no definitive diagnostic tools, such as laboratory tests or radiographic assessments. Osteopenia and patchy osteoporosis, which can be detected on three-phase bone scans, can be seen in the early stage. Sweat testing, diagnostic sympathetic blocks, and quantitative sensory testing can be useful for the examination of CRPS. The important treatment strategies are: 1) patient education for self-management (Table 2);2) physical vocational rehabilitation; 3) pain relief (medication); and 4) psychological intervention [11].

Our patient underwent proper management of CRPS 
with the morphine pump and weekly medication. Her pain incomprehensibly continued for approximately $4 \mathrm{~h}$, including $55 \mathrm{~min}$ of general anesthesia and a total of 2 h $30 \mathrm{~min}$ of two sedations. The pain was not located at the treatment site of the dental procedure. Although the major factor relieving pain was unknown, attention is drawn to the pharmacological effects of ketamine, which was used for the second sedation.

Ketamine has diverse mechanisms underlying an analgesic effect, including NMDAR antagonism, opioid receptor agonism, local anesthetic action, sigma receptor interaction, cholinergic effects, and other effects. Several studies suggested that the NMDAR antagonism effect of ketamine plays a major role in its analgesic function and in activating and upregulating the spinal-cord central sensitization. Ketamine is currently the only potent clinically available NMDAR antagonist. Some studies have shown long-term effects of ketamine, especially for type 1 CRPS [12]. The effect of ketamine on acute pain directly correlates with its plasma concentration and disappears rapidly upon termination of infusion [13]. The differential findings of ketamine on spontaneous pain in type 1 CRPS may suggest that these effects are obtained from long-term desensitization of NMDAR in the central nervous system. However, ketamine has psychomimetic side effects, such as hallucination, which limits its use.

Dexmedetomidine is an $\alpha 2$-adrenergic receptor agonist, which was initially approved as a sedative agent for use in the intensive care unit. In recent studies, intraoperative dexmedetomidine infusion caused a significant reduction in the need for both intraoperative and postoperative analgesics [14]. In several reports, the effects of dexmedetomidine on the treatment of acute pain in CRPS are also favorable [15]. Most studies reported a combination with ketamine or other analgesics while some studies reported administration of dexmedetomidine alone for acute pain. Dexmedetomidine has a short elimination half-life, and its analgesic effect is unclear compared to its sedation effect. Dexmedetomidine may not have been effective for the present patient.

We presented a rare case of dental treatment of a patient with CRPS under general anesthesia and reported management of pain that was not associated with the treatment area. The patient was diagnosed with type 1 CRPS and underwent various treatments, including morphine-pump implantation. The pain developed from a minor injury before the induction of general anesthesia and persisted for $4 \mathrm{~h}$. Remifentanil (potent ultra-shortacting opioid), propofol (short-acting intravenous general anesthetic), and dexmedetomidine (highly selective $\alpha$ 2-adrenergic receptor agonist, sedatives) were used, but the pain did not reduce. Ketamine used for the second sedation provided pain reduction, and the patient was discharged through the normal pathway.

\section{AUIHOR ORELID:}

Seung-Hyun Rhee: https://orcid.org/0000-0001-6210-1796

Sang-Hun Park: https://orcid.org/0000-0003-0207-4807

Sung-Ho Ha: https://orcid.org/0000-0002-3270-477X

Seung-Hwa Ryoo: https://orcid.org/0000-0002-7442-8531

Myong-Hwan Karm: https://orcid.org/0000-0002-7494-4747

Hyun Jeong Kim: https://orcid.org/0000-0002-9265-7549

Kwang-Suk Seo: https://orcid.org/0000-0001-5906-0639

DECLARATION OF INTEREST: The authors declare that they have no financial or competing interests.

\section{REFERENCES}

1. Marinus J, Moseley GL, Birklein F, Baron R, Maihöfner C, Kingery WS, et al. Clinical features and pathophysiology of complex regional pain syndrome. Lancet Neurol 2011; 10: 637-48.

2. Boas RA. Complex regional pain syndromes: Symptoms, signs, and differential diagnosis. Seattle, WA. IASP Press. 1996, pp 79-92.

3. Merskey $\mathrm{H}$. Classification of chronic pain; description of chronic pain syndromes and definitions of pain terms. IASP Task Force on Taxonomy 1994; 41-3

4. Urits I, Shen AH, Jones MR, Viswanath O, Kaye AD. 
Complex regional pain syndrome, current concepts and treatment options. Curr Pain Headache Rep 2018; 22: 10.

5. Harden RN, Bruehl S, Perez RS, Birklein F, Marinus J, Maihofner C, et al. Validation of proposed diagnostic criteria (the "budapest criteria") for complex regional pain syndrome. Pain 2010; 150: 268-74.

6. De Mos M, De Bruijn A, Huygen F, Dieleman J, Stricker BC, Sturkenboom M. The incidence of complex regional pain syndrome: A population-based study. Pain 2007; 129: 12-20.

7. Mackey S, Feinberg S. Pharmacologic therapies for complex regional pain syndrome. Curr Pain Headache Rep 2007; 11: 38-43.

8. Okada M, Suzuki K, Hidaka T, Shinohara T, Kataharada $\mathrm{K}$, Takada $\mathrm{K}$, et al. Complex regional pain syndrome type I induced by pacemaker implantation, with a good response to steroids and neurotropin. Intern Med 2002; 41: 498-501.

9. Klega A, Eberle T, Buchholz H-G, Maus S, Maihöfner C, Schreckenberger M, et al. Central opioidergic neurotransmission in complex regional pain syndrome. Neurology 2010; 75: 129-36.
10. Goebel A. Complex regional pain syndrome in adults. Rheumatology 2011; 50: 1739-50.

11. Turner-Stokes L, Goebel A. Complex regional pain syndrome in adults: Concise guidance. Clin Med 2011; 11: 596-600.

12. Schwartzman RJ, Grothusen J, Kiefer TR, Rohr P. Neuropathic central pain: Epidemiology, etiology, and treatment options. Arch Neurol 2001; 58: 1547-50.

13. Sigtermans MJ, Van Hilten JJ, Bauer MC, Arbous MS, Marinus J, Sarton EY, et al. Ketamine produces effective and long-term pain relief in patients with Complex Regional Pain Syndrome Type 1. Pain 2009; 145: 304-11.

14. Massad IM, Mohsen WA, Basha AS, Al-Zaben KR, Al-Mustafa MM, Alghanem SM. A balanced anesthesia with dexmedetomidine decreases postoperative nausea and vomiting after laparoscopic surgery. Saudi Med J 2009; 30: $1537-41$.

15. Azari P, Lindsay DR, Briones D, Clarke C, Buchheit T, Pyati S. Efficacy and safety of ketamine in patients with complex regional pain syndrome. CNS drugs 2012; 26: 215-28. 